\title{
Social Networks among Elderly Women: Implications for Health Education Practice
}

\author{
Barbara A. Israel, Dr.P.H. \\ University of Michigan \\ Department of Health Behavior and Health Education \\ School of Public Health
}

Carol C. Hogue, Ph.D.

Duke University

Ann Gorton, Ph.D.

Wayne State University

\begin{abstract}
The general aim of the present study was to examine and help clarify the properties of the distinctions between social networks and social support, their relationship to health status, and their implications for health education practice. More specifically, a secondary data analysis was conducted with 130 white women, community residents, between the ages of 60 and 68 , which examined the relationship between psychological well-being and social network characteristics. These characteristics are categorized along three broad dimensions: structure-links in the overall network (size and density); interactionnature of the linkages themselves (frequency, homogeneity, content, reciprocity, intensity, and dispersion); and functions which networks provide (affective support and instrumental support). A combination was made and relative strength investigated of several network characteristics representative of the quality of interactions (i.e., reciprocal affective support, intensity, and affective support) and those representing the quantity of interactions (i.e., size, density, and frequency).

Of all these network characteristics, controlling for the cumulative effect of marital status, income, employment background, perceived health status, and use of network, only reciprocal affective support, intensity, and affective support explained a significant amount of variance in psychological well-being. The combination of qualitative net-
\end{abstract}

We wish to acknowledge the important contributions made to this study by Guy $W$. Steuart, Berton H. Kaplan, and Bill Ware, and the editorial assistance provided by Noreen Clark and Richard Pipan. 
work characteristics was more strongly related to psychological wellbeing than the effect of the combined quantitative factors.

A discussion of the results of the study, limitations, and application of the findings to health education is included. Particular emphasis is given to the role of the health educator in identifying and collaborating with social networks in ways which recognize, support, and strengthen them and yet do not undermine these natural systems.

\section{PSYCHOSOCIAL DETERMINANTS OF WELL-BEING}

During the past twenty-five years, numerous research studies conducted in several fields have identified various psychosocial factors as predictors of health and mental health status. These include: (a) stress, (b) social support and social networks, (c) competence, (d) socioeconomic status and (e) coping. ${ }^{1-11}$ For example, loss of a spouse (stress) may be related to depression for one individual and high blood pressure for another person, while a third person may experience no significant effects on his or her well-being.

One factor that has gained prominence in the last decade as having a potentially direct and/or buffering effect on physical and psychological well-being is social support. ${ }^{11,13-17}$ Although the cumulative evidence is highly suggestive of the significance of social support, there is considerable disagreement and confusion with regard to definition, role, and measurement of such terms as social support, social networks, social support systems, and support networks. A clarification of the properties and distinctions of these terms, their relationship to health status, and their implications for practice is needed. This was the general aim of the present study, which focused on the characteristics of social networks and their association with psychological wellbeing among a sample of elderly women

\section{RESEARCH PROBLEM: \\ SOCIAL NETWORKS AND SOCIAL SUPPORT_DIFFERENCES AND STUDY EMPHASIS}

Mitchell ${ }^{18}$ defines a social network "as a specific set linkages among a defined set of persons with the additional property that the characteristics of these linkages as a whole be used to interpret the social behavior of the person involved" (p.2). In accordance with this definition, for the purposes of this study, a 
social network was viewed as person-centered and comprised of numerous characteristics along three broad dimensions: ${ }^{18,19}$ (1) structure- links in the overall network, e.g., size and density; (2) interaction-the nature of the linkages themselves, e.g., frequency and reciprocity; and (3) functions which networks provide, e.g., affective support, tangible aid, and services. The purpose of this research was to examine the relationship between psychological well-being and each of eleven network characteristics. A social network then refers to human interactions, some or all of which may or may not provide social support.

It is the functions which networks provide that establish the link with the concept of social support. These functional characteristics, as described in the literature, ${ }^{15,19-22}$ are defined below:

1. Affective support: the provision of moral support, caring, and love

2. Instrumental support: the provision of tangible aid and services, e.g., loan of money, food, help with child care

3. Cognitive support: access to diverse information, new knowledge, advice and feedback

4. Maintenance of social identity: validation of a shared world view

5. Social outreach: access to social contacts and social roles

These characteristics are most frequently defined in terms which imply that their presence is positively related to health status. It is important to recognize that networks which do not provide functions and/or provide "negative" ones (e.g., dominance rather than caring, advice when it is not wanted) may be negatively related to health status.

Frequently cited definitions of social support are quite similar to the functional characteristics of social networks. Cobb ${ }^{13}$ refers to social support as information that leads people to believe that they are cared for, loved, esteemed, and valued, and that they belong to a network of communication and mutual obligation. Similarly, Kahn and Antonucci ${ }^{23}$ define social support as interpersonal transactions that consist of at least one of three characteristics: affect (love, respect), affirmation (acknowledgement of appropriateness of actions or statements), and aid (money, tangible items, information). Building on these definitions, House ${ }^{17}$ defines the content of four broad classes or types of supportive behavior or acts: emotional support (affect, esteem, concern), appraisal support (feedback, affirmation), informational support 
(suggestion, advice, information), and instrumental support (aid in labor, money, time).

Recently, convincing arguments have been made that the examination of social networks and their relationships to well-being can be advantageous. ${ }^{24-29}$ The major points of these arguments which were most applicable to the decision to take a network analytic approach in this study are stated below:

1. numerous network characteristics could be examined to determine their relationship to psychological well-being;

2. the context (structure and interaction) within which social support might be provided could be investigated;

3. the quantity and quality of network characteristics and their association with psychological well-being could be examined comparatively;

4. the results of the examination of network characteristics might provide insights for resolving the conceptual and measurement difficulties regarding the concept of social support; and

5. the network characteristics important for interventions aimed at enhancing psychological well-being could be delineated.

\section{EXPLANATION OF VARIABLE AND PREVIOUS RESEARCH FINDINGS}

Numerous characteristics of social networks are discussed in the literature. As stated previously, these can be categorized into three broad areas: structure, interaction, and function. . $^{\mathbf{3 9}, 40}$ Structural charcteristics refer to the links in the network. Those examined in this study were: size, the number of direct contacts of the individual, and density, the ratio of persons who could know another one (links which could exist) to the persons who actually know one another (links do exist). Interactional characteristics refer to the nature of the links themselves. Those examined in this study were: content, the meanings that persons in a network give their relationships (e.g., neighbor, friend, coworker); directedness, the reciprocity in a relationship; intensity, degree of intimacy and emotional intensity of ties; frequency, the number of contacts between persons within a network; homogeneity, the extent to which network members share social attributes (e.g., age, sex, ethnicity, and social class); and dispersion, ease with which network members can make 
face-to-face contacts. Functional characteristics address the functions that networks provide. Those included in this study were: instrumental support, provision of tangible aid and services, and affective support, provision of emotional and moral support.

An extensive review of the literature regarding these social network characteristics and well-being is beyond the scope of this paper. Only a few relevant findings will be presented below. For additional examples and more depth, the reader is referred to the following reviews; references 22,27,30-32.

Much of the early research on social networks was exploratory and descriptive; in general, it was found that high-density networks ("close-knit") strongly influence an individual's conformity to norms shared by network members and provide more instrumental and affective support in both everyday and crisis situations than do less dense networks. This provision of support was also found to be associated with larger size, less dispersion (closer geographic proximity), greater homogeneity, and reciprocity within networks. ${ }^{33-39}$

Other research has specifically examined the relationship between social interaction and social participation (factors similar to the network characteristics of size and frequency) and wellbeing among the elderly. However, these investigations have not been within the broader social network context and the results have been inconclusive. ${ }^{40-43}$ Many of the studies that have used a network analytic approach have focused on the structural and interactional characteristics of networks in relation to health status and have also had varying results. ${ }^{19,43-50}$ As a response to these studies, several authors have suggested that part of the reason empirical findings have been so conflicting is that it is not the quantity (size and frequency) of social interactions which is associated with psychological well-being in old age, but rather the quality (meaning, intensity, mutual sharing), and they call for further examination of such qualitative factors. ${ }^{43,51-52}$ This suggestion is supported theoretically by symbolic interactionism and exchange theory ${ }^{31.32 .53-60}$ and also empirically. Study results stemming from examination of the association between the qualitative interactional characteristics of networks, i.e., intensity and reciprocity, and well-being include: (a) both intensity and reciprocity are positively associated with mental health status; ${ }^{19}$ (b) reciprocity with affective support is predictive of depression but intensity is not ${ }^{\text {th }}$ (c) reciprocity is significantly related to mental health status; ${ }^{45,49}$ (d) presence of a confidant (similar to intensity) is positively associated with psychological well-being in an elderly general population; ${ }^{62.63}$ and (e) in an elderly population, 
the association between objective or quantitative properties of social networks and morale is mediated by a person's subjective or qualitative social integration-including the network characteristic of intensity. ${ }^{51}$

Social network research which has investigated the relationships between networks and health status has primarily focused on structural and interactional characteristics. The social support literature has examined factors similar to functional network characteristics, e.g., affective and instrumental support. Such research has measured the presence or absence of support in general, not within a specific network context. However, the numerous findings that social support is positively related to health status $3,11,13,14,17,48,64-66$ do suggest the value of investigating the functional dimensions of social networks.

Based on the results of this literature, as cited above, the current study chose to examine each of eleven network characteristics, as categorized according to structure, interaction, and function, and their relationship to psychological well-being.

For the purpose of this study, psychological well-being, the dependent variable, is defined in accordance with Bradburn ${ }^{67}$ in terms of both positive and negative aspects of an individual's situation. Therefore, not only do negative factors such as anxiety and worry influence psychological well-being, but positive factors such as self-esteem and feeling loved also have an impact.

Several personal and environmental factors which were considered to be potential predictors of network characteristics and/or well-being were included as control variables. They were: use of network; ability to accept affective support; physical health status; and sociodemographic factors.

\section{HYPOTHESES}

Based upon theory and research as discussed above and the conceptual framework developed for this investigation, ${ }^{31}$ the following hypotheses were posited:

1. Each of the eleven network characteristics separately is positively associated with psychological well-being, e.g., size density, homogeneity, affective support. (This is actually eleven separate hypotheses.)

2. Qualitative network characteristics (i.e., reciprocal affective support, intensity, and affective support) in combination are expected to be better predictors of psycholog- 
ical well-being than quantitative characteristics (i.e., size, density, and frequency of interactions) in combination.

\section{METHODOLOGY}

The present investigation was carried out using data collected by Hogue and Gorton. ${ }^{68}$ That study used network analysis to examine the interrelationships between stress, social support, adjustment to retirement, and psychological well-being, among a sample of elderly women.

\section{Selection of Subjects}

The criteria used for selecting the sample were that the respondents be white women between the ages of sixty and sixtyeight; approximately half had to be retirees who had stopped work two months to five years before the interview and were not engaged in any work outside the home during the last ten years. Since the distinction between the two subsamples was not of primary importance in this study, the subjects were combined into one sample, using employment background as a control variable.

Most of the subjects (72\%) were obtained from a Durham, North Carolina 1977 voter registration list. Retirement rosters of Duke University and General Telephone and Electric Company were also used to recruit retirees $(18 \%)$. The remainder of the study population $(10 \%)$ was obtained from contacts made at housing units for the elderly and a subject list of the Center for the Study of Aging at Duke. Thus, it was not a probability sample. One hundred and thirty women were studied; seventy-five recent retirees and fifty-five not recently employed.

\section{Data Collection}

Five women were trained in interviewing techniques before and during the data collection period. These women conducted 130 home interviews from June to September of 1979. The average interview length was two hours, with a range of from fifty minutes to almost four hours.

The interviewer asked the respondent questions for obtaining names of network members involved in the various social exchanges, the delineation of the close network, and the identification of network characteristics and obtained sociodemo- 
graphic information. The respondent completed a selfadministered questionnaire which included the measures of psychological well-being, ability to accept affective support, and physical health status.

\section{Variables in the Study}

The independent variables of this study were the characteristics of the respondent's close interpersonal network. The close network consisted of up to five individuals the respondent felt closest to and most able to confide in and receive moral support from. (See instrumentation section for description of how the close network was delineated.) The decision to examine only the close network was based on the assumption that if psychological well-being is related to the characteristics of any network, such relationships would be present especially in the close network. The operational definition of each of the network characteristics examined is provided in Appendix 1.

The dependent variable was psychological well-being, which was operationally defined for the purposes of this study in terms of psychological states (feelings) rather than somatic complaints and functional status, which have been used to define psychological well-being in other general population studies. ${ }^{69-73}$ Psychological well-being was further defined as the balance between positive states (e.g., feeling proud, interested, on top of the world) and negative states (e.g., feeling upset, depressed and restless). Therefore, psychological well-being wa considered to be a combination of both positive and negative feelings.

The relationships between the independent and dependent variables were examined with control for: demographic characteristics (income level, employment background, marital status); physical health status; and use of network members. Additionally, ability to accept affective support was a control for the functional characteristic of affective support.

Use of network was defined as the extent to which an individual talks about personal matters with and seriously considers the advice of network members. Ability to accept affective support was defined by the extent to which an individual feels comfortable or uncomfortable when members of their network show warmth or friendliness, listen attentively, and show approval. Physical health status was defined as a combination (additive) of four dimensions of perceived health status (i.e., overall health at present time, health now as compared to five years ago, health 
troubles interfering with activities, and health compared with other people of the same age).

\section{Instrumentation: Independent Variables}

In order to obtain information about the social networks of the subjects, $\mathrm{Hogue}^{74}$ and Gordon ${ }^{68,75}$ applied the egocentric network methodology described by Fisher and his colleagues. ${ }^{76-78}$ This egocentric network analytic method elicits networks first of all by asking the respondent to give names of persons with whom he or she shares various types of exchanges. Examples of the types of exchanges in which the subjects of this study were asked about include: who helps out with tasks around the house; with whom does she get together to talk about hobbies or interests; whom does she talk with about personal matters; whose opinions does she consider when making important decisions; who takes care of her when she is sick; who lends her money; and who provides transportation. Questions were also asked to identify whom the subject helped as well as who helped the subject.

The respondent also responded about the meaning she applies to each relationship, the distance she lives form each network member, and how close she feels to each network member.

The names elicited by this method were then combined into one list of the full network. The respondent was then asked to name anyone else who is important to her that did not show up on the list, and to examine the full network list and select up to five people in descending order whom "you feel very close to now." The names elicited made up the respondent's close network. Furthermore, for each person in the close network, information was obtained for the remaining network characteristics.

\section{Instrumentation: Dependent Variable}

Psychological well-being was measured by the Affect Balance Scale (ABS), developed by Bradburn and Caplovitz ${ }^{79}$ and Bradburn. ${ }^{67}$ This scale measures an individual's position on two independent dimensions - positive affect and negative affect; psychological well-being is the extent to which positive feelings outweigh negative feelings. This scale was considered an appropriate measure for this study based on numerous validity and reliability tests and analyses ${ }^{67,71,80,81}$ many of which specifically 
addressed the applicability of the Affect Balance Scale with an elderly population. ${ }^{63,82,83}$

\section{Instrumentation: Control Variables}

A series of questions were used to measure the control variables-marital status, income level, use of network, employment background, ability to accept affective support, and physical health status. The four questions asked which made up the ability to accept affective support dimension were drawn from the study of Caplan et al. ${ }^{84}$ of the relationship between social support and a patient's adherence to medical regimen. The Older American Resource Survey (OARS) Overall Physical Health Assessment scale ${ }^{\text {95 }}$ was used to measure physical health status. This physical health assessment scale obtains a subjective health rating of an individual's perceived health status.

\section{Data Analysis}

Basic univariate statistics (range, medians, and standard deviations) of the network characteristic variables, control variables, and psychological well-being were examined. Multiple regression analysis were carried out to test the hypotheses.

For each hypothesis, the control variables (income, marital status, employment background, use of network, and perceived health status) were first entered into the model, followed by the specific network characteristic variable being tested. Using the SAS statistical package, ${ }^{86}$ the procedures followed to test if a given network characteristic variable had a significant effect involved first examining cumulatively across the control variables the Type 1 sum of squares, mean square, and resulting $F$ statistic. It was then determined whether or not the Type 1 sum of squares, mean square, and resulting $F$ statistic for the network variable explained a significant amount of variance in affect balance above and beyond the cumulative contribution of the control variables. Since this was the approach taken, rather than an examination of a model which included all variables together, there is no relevant $R^{2}$ statistic to report. Also, for each hypothesis, the interactions between the network characteristic variable and controls and the correlations among all the variables were examined. To identify the unique contribution made by each individual control variable, adjusting for all the other controls, a multiple regression procedure was used that examined the Type IV sum 
of squares, mean square, and resulting F statistic. In this study, the alpha level for hypothesis testing was set at .05.

\section{RESULTS}

\section{Demographic Characteristics}

A compilation of the general demographic characteristics of the study population is as follows. The mean age was 64.15 years; $68.5 \%$ of the respondents were married, and $22.3 \%$ were widowed. The median number of years of education was 12, with $13 \%$ of the sample having had more than 16 years. Occupational status was obtained for the subject's main job, and $39.8 \%$ were categorized as clerical, $25.2 \%$ were categorized as professionals and $10.6 \%$ as managers. The income of $32.3 \%$ of the respondents was greater than $\$ 15,000$. Ninety-five point four percent of the respondents were Protestant.

\section{Hypothesis Testing}

As expected, in carrying out the multiple regression analyses, the control variables (income, marital status, employment background, use of network, and perceived health status) cumulatively did account for a significant amount of the variance in the dependent variable, psychological well-being. Beyond their effect, in examining separately the relationship between each of the eleven network characteristics and psychological well-being, the only variables that made an additional contribution were reciprocal affective support, intensity, and affective support.

As indicated in Table 1, affective supportive linkages which are predominantly reciprocal do explain a significant amount of variance in psychological well-being above and beyond the control variables, $F(1,103)=7.52, p<.01$. Table 2 indicates that controlling for the effects of other variables, the intensity (closeness) of relationships within a network does explain a significant amount of variance in the dependent variable, $F(1,107)=6.55$, $p<.01$. As presented in Table 3, strong affective support does explain the variance in affect balance, above and beyond the control variables, $F(1,103)=6.83, p<.01$.

In combination, these same three variables, which were defined as qualitative characteristics of networks, were found (as hypothesized) to be a better predictor of psychological well- 
MULTIPLE REGRESSION ANALYSIS OF SIX VARIABLES

WITH AEFECT BALANCE SCORES: RECIPROCAL AFFECTIVE SUPPORT $(\mathrm{n}=122)$

\begin{tabular}{|c|c|c|c|c|}
\hline Variables & SS & $d f$ & MS & $\mathrm{F}^{1}$ \\
\hline Control Variables & 98.24 & 9 & 10.92 & $3.59 \div$ \\
\hline \multicolumn{5}{|l|}{$\begin{array}{l}\text { Income } \\
\text { Marital Status } \\
\text { Employment Background } \\
\text { Use of Network } \\
\text { Perceived Health Status }\end{array}$} \\
\hline Main Effect & 22.87 & 1 & 22.87 & $7.52 \cdots$ \\
\hline \multicolumn{5}{|l|}{$\begin{array}{l}\text { Reciprocal Affective } \\
\text { Support }\end{array}$} \\
\hline Interactions & $53.53^{a}$ & 8 & 6.69 & $2.20 \div 6$ \\
\hline $\begin{array}{l}\text { Income } \times \text { Reciprocal } \\
\text { Affective }\end{array}$ & $3.27^{b}$ & 1 & 3.27 & 1.08 \\
\hline $\begin{array}{l}\text { Marital Status } x \\
\text { Reciprocal Affective }\end{array}$ & $23.12^{b}$ & 3 & 7.71 & 2.53 \\
\hline $\begin{array}{l}\text { Employment Background } x \\
\text { Reciprocal Affective } \\
\text { Use } x \text { Reciprocal }\end{array}$ & $5.34^{b}$ & 2 & 2.67 & .88 \\
\hline $\begin{array}{l}\text { Use } x \text { Reciprocal } \\
\text { Affective }\end{array}$ & $7.26^{\mathrm{b}}$ & 1 & 7.26 & 2.39 \\
\hline $\begin{array}{l}\text { Perceived Health } x \\
\text { Reciprocal Affective }\end{array}$ & $9.59^{\mathrm{b}}$ & 1 & 9.59 & 3.15 \\
\hline Error & 313.23 & 103 & 3.04 & \\
\hline
\end{tabular}

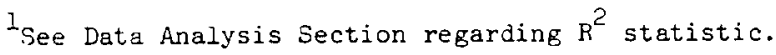

Q Type I SS

Type IV SS

$c^{c}$ Effect explained elsewhere. ${ }^{31}$

${ }^{*} \mathrm{p}<.05$

${ }^{*} p<.01$ 
TABLE 2

MULTIPLE REGRESSION ANALYSIS OF SIX VARIABLES WITH AFFECT BALANCE SCORES: INTENSITY $(\mathrm{a}=126)$

\begin{tabular}{|c|c|c|c|c|}
\hline Variables & SS & $d f$ & MS & $F^{1}$ \\
\hline Control Variables & 100.18 & 9 & 11.13 & $3.34 \%$ \\
\hline \multicolumn{5}{|l|}{$\begin{array}{l}\text { Income } \\
\text { Yarital Status } \\
\text { Employment Background } \\
\text { Use of Network } \\
\text { Perceived Health Status }\end{array}$} \\
\hline Main Effect & 21.81 & 1 & 21.81 & $6.55 \div$ \\
\hline \multicolumn{5}{|l|}{ Intensity } \\
\hline Interactions & 15.65 & 8 & 1.95 & .59 \\
\hline \multicolumn{5}{|l|}{$\begin{array}{l}\text { Income } x \text { Intensity } \\
\text { Marital Status } x \\
\text { Intensity } \\
\text { Employment Background } x \\
\text { Intensity } \\
\text { Use } x \text { Intensity } \\
\text { Perceived Health } x \\
\text { Intensity }\end{array}$} \\
\hline Error & 356.08 & 107 & 3.33 & \\
\hline
\end{tabular}

${ }^{1}$ See Data Analysis section regarding $\mathrm{R}^{2}$ statistic.

$*_{p}<.01$ 
TABLE 3

MULTIPLE REGRESSION ANALYSIS OF SEVEN VARIABLES

WITH AFFECT BALANCE SCORES: AFFECTIVE SUPPORT $(a=122)$

\begin{tabular}{|c|c|c|c|c|}
\hline Variables & SS & $d f$ & MS & $F$ \\
\hline Control Variables & 98.24 & 9 & 10.92 & $3.49 \%$ \\
\hline \multicolumn{5}{|l|}{$\begin{array}{l}\text { Income } \\
\text { Marital Status } \\
\text { Employment Background } \\
\text { Use of Network } \\
\text { Perceived Health Status } \\
\text { Ability to Accept } \\
\text { Affective Support }\end{array}$} \\
\hline Main Effect & 21.33 & 1 & 21.33 & $6.83 \div$ \\
\hline \multicolumn{5}{|l|}{ Affective Support } \\
\hline Interactions & 46.59 & 8 & 5.82 & 1.87 \\
\hline $\begin{array}{l}\text { Income } x \text { Affective } \\
\text { Support } \\
\text { Marital Status } x \\
\text { Affective Support } \\
\text { Employment Background } x \\
\text { Affective Support } \\
\text { Use } x \text { Affective Support } \\
\text { Perceived Health } x \\
\text { Affective Support } \\
\text { Ability to Accept } x \\
\text { Affective Support }\end{array}$ & & & & \\
\hline Error & 321.72 & .03 & 3.12 & \\
\hline
\end{tabular}

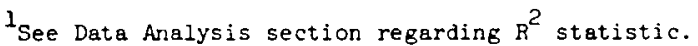

${ }_{p}<.01$ 
TABLE 4

MUTIPLE REGRESSION ANALYSIS OF ELEVEN VARIABLES

WITH AFFECT BALANCE SCORES: QUANTITATIVE AND QUALITATIVE $(n=115)$

\begin{tabular}{|c|c|c|c|c|}
\hline Variables & SS & $d f$ & MS & $\mathrm{F}^{1}$ \\
\hline Control Variables & 86.73 & 8 & 10.84 & 3.26 \\
\hline \multicolumn{5}{|c|}{$\begin{array}{l}\text { Income } \\
\text { Marital Status } \\
\text { Employment Background } \\
\text { Use of Network } \\
\text { Perceived Health Status }\end{array}$} \\
\hline Quantitative Variables & 2.00 & 3 & .67 & .20 \\
\hline \multicolumn{5}{|l|}{$\begin{array}{l}\text { Size of Close Network } \\
\text { Density } \\
\text { Frequency }\end{array}$} \\
\hline Qualitative Variables & 45.47 & 3 & 15.16 & 4.57 \\
\hline \multicolumn{5}{|c|}{$\begin{array}{l}\text { Affective Support } \\
\text { Reciprocal Affective Support } \\
\text { Intensicy }\end{array}$} \\
\hline Error & 332.38 & 100 & 3.32 & \\
\hline
\end{tabular}

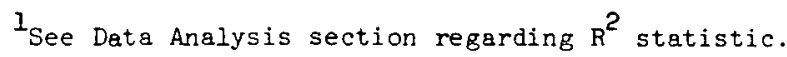

$*_{p}<.01$ 
TABLE I

SOCIAL NETWORK CHARACTERISTICS: OPERATIONAL DEFINITIONS

\section{Structural}

1. Size. . . . . . . Number of persons in close aetwork.

2. Density . . . . . . Proportion of people within close network who know one another

\section{Interactional}

3. Homogeneity...... Extent to which the ego and close network nembers are the same along dimensions of marital status, employment background, occupation, education, and religion (averaged across the close network)

4. Content. . . . . . Meanings that ego member of the network assigns to relationships, i.e. relative, neighbor, volunteer associate, co-worker, other--uniplex linkages having only one meaning, multiplex having more than one (averaged across the close network)

5. Reciprocal Affective

$$
\begin{aligned}
\text { Support. . . . . Extent to which the ego's affective } & \text { support relationships with network } \\
& \text { members are reciprocal, e.g. mutual } \\
& \text { exchange of moral support (averaged } \\
& \text { across the close network) }
\end{aligned}
$$


APPENDIX I, TABLE I (continued)

Concept Operationalization

6. Reciprocal Instrumental

Support........ Extent to which the ego's instrumental support relationships with network members are reciprocal, e.g., mutual exchange of goods and sexvices (averaged across the close network)

7. Intensity....... Degree of closeness which ego member assigns to relationstips withio network (averaged across the close network)

8. Frequency....... How of ten the ego member talks on the telephone and sees others in the close network (averaged across the close network)

9. Dispersion....... Geographic distance in terms of time it takes for the ego to reach network members (averaged across the close network)

\section{Functional}

10. Affective Support.... Extent to which ego counts on network members for moral support (averaged across the close network)

11. Instrumental Support. .. Extent to which ego has been belped by network members with specific tasks, i.e. housebold chores, transportation, care when sick, etc (averaged across the close network) 


\section{APPENDIX II}

\section{TABLE I}

EIGHT MULTIPLE REGRESSION ANALYSES

OF INDEPENDENT VARIABLES WITH AFFECT BALANCE SCORES ${ }^{8}$

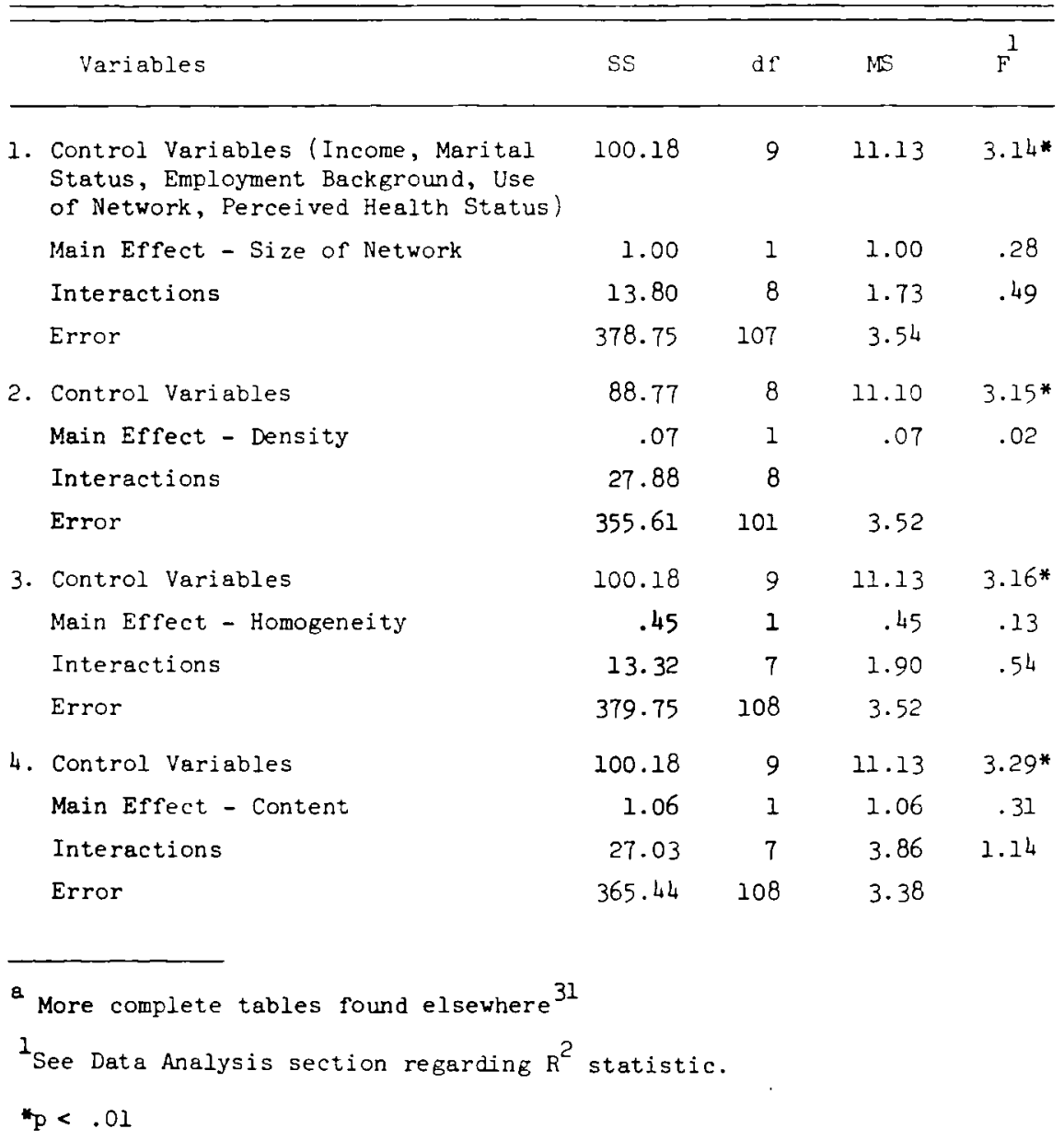


APPENDIX II, TABLE I (continued)

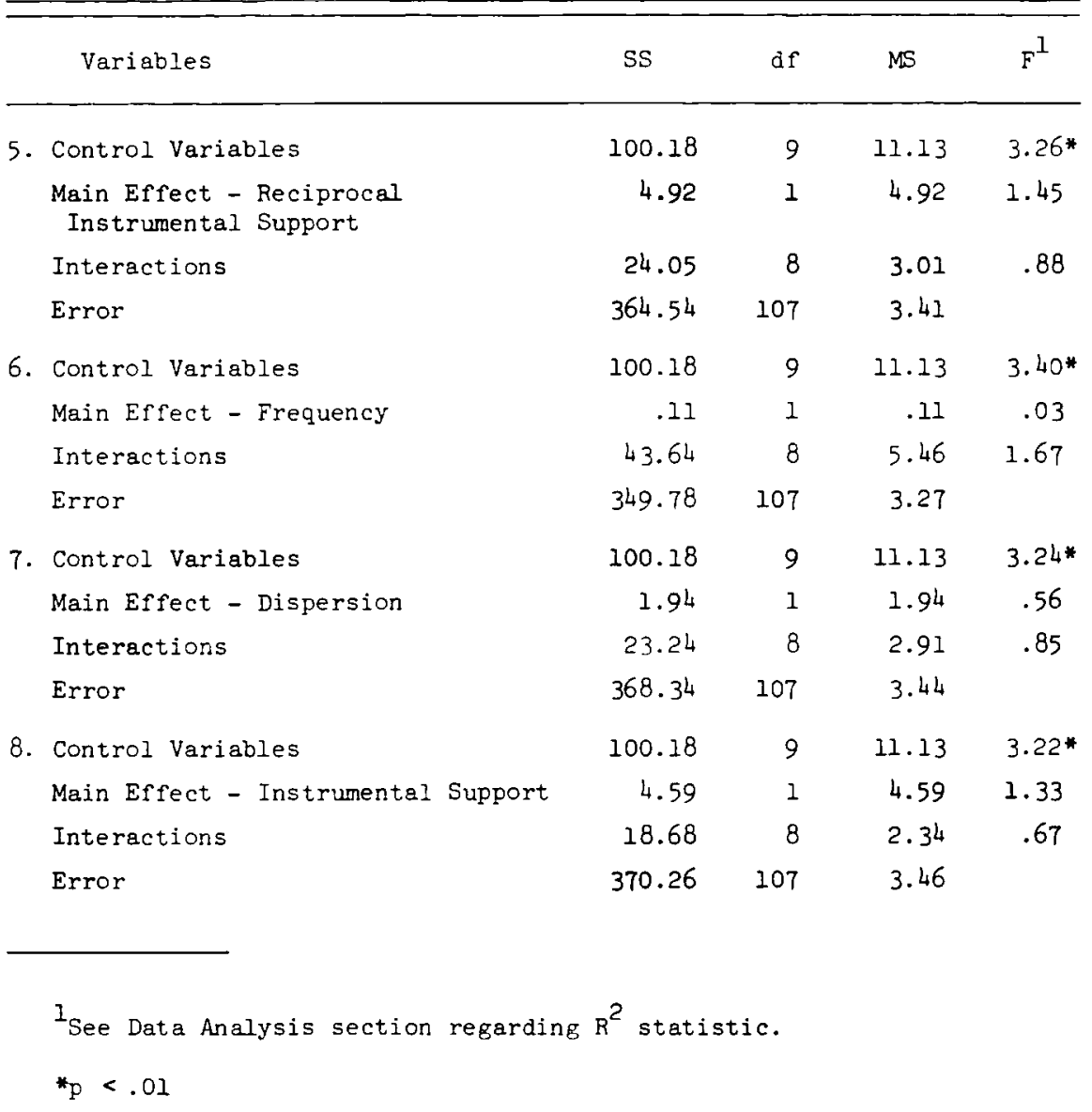


being than a composite of quantitative variables, $F(3,100)=4.57$, $p<.01$ (Table 4). [The results of each regression analysis conducted for the other network characteristics (in which the hypothesized relationships were not found) are presented in Table 1 of Appendix II.]

\section{Control Variables: Individual Contributions}

As we discussed previously, the control variables selected for this study were based on empirical findings. Although no specific hypotheses were posited for testing here, it is interesting to examine the individual contribution that each of these control variables made in explaining the dependent variable. Of the five control variables, use of network $[F(1,116)=5.23, p<.05]$ and perceived health status $[F(1,116)=8.78, p<.01]$ each provided a significant explanation of the variance in affect balance above and beyond the other control variables.

\section{DISCUSSION}

The hypotheses which posited a relationship between psychological well-being and each of the following network characteristics were not supported by the data in this study-size, density, homogeneity, content, reciprocal instrumental support, frequency, dispersion, and instrumental support. Although the evidence appeared to be sufficient to develop such hypotheses, there have also been contradictory findings in other research which were similar to the results here. ${ }^{19,43,50,61}$ Such results suggest that properties regarding the quantitative aspects of social networks may not be strongly associated with health status.

With regard to the nonsignificant findings concerning homogeneity and content characteristics, a partial explanation might be that the measures used did not tap the perhaps more important subjective dimensions. For example, homogeneity measured in terms of perceived similarity of values and norms aong network members might be more appropriate and result in significant findings as compared to homogeneity measured by similarity along such social attributes as education level, religious preference, and marital status.

A possible explanation for the lack of significance found with the content, size, and density characteristics is that there is a lack of variability of scores with this sample. It can be speculated that a group with more heterogeneity on these variables might yield different results. 
Two other hypotheses that were not supported by this research included the network characteristics of instrumental support and reciprocal instrumental support. These findings would tend to support the thinking that not only do networks provide different types of support but also that the different types of support have different effects. Therefore, although instrumental support may not be related to psychological well-being, it may be influential in some other aspect of human behavior and wellbeing. These results coincide with the suggestions made by Dean and $\operatorname{Lin}^{87}$ and LaRocco et al. ${ }^{66}$ that from the perspective of health, emotional and expressive supportiveness is more important than instrumental assistance. One further consideration, however, is the possible lack of independence between affective and instrumental support. In this study, they were significantly correlated $(r=.2995, p<.001)$; yet when examined together in a regression model, instrumental support on its own did not explain a significant amount of the variance in psychological well-being, and affective support did make a significant unique contribution in explained variance above and beyond instrumental support $(F(1.119)=4.72, p<.05)$. What this might indicate is that different types of support might be provided by the same individuals. Therefore, they are not independent; but some types (affective) are more strongly associated with psychological wellbeing than others (instrumental). This discussion also helps explain the finding from this study that affective support is significantly related to psychological well-being. Other research ${ }^{66,88}$ has had similar results.

The network characteristic of reciprocal affective support was also found to be associated with psychological well-being. Several studies have found the general concept of reciprocity to be an important property of interactions. ${ }^{19,39,49,61,70,89,108}$ This result especially lends further evidence to an exchange theory interpretation of human attitudes, beliefs, and behaviors. According to exchange theory, a key influence on these human dimensions is the degree of reciprocity in exchanges between persons. The more rewards the interaction provides as compared to the costs, the more likely the relationship is reciprocal and not dependent and the greater the possibility for its positively influencing behavior and well-being. This is particularly important to consider with an elderly population; older people frequently either actually have fewer resources to exchange or perceive that they do, and society often assigns reduced status to them and their ability to reciprocate..$^{59,60}$

Intensity was the other individual network characteristic which was found in this study to be related to psychological well-being. 
This concept of the degree of emotional closeness is similar in definition and result to the studies that examined the effect of having a confidant. ${ }^{51,62.63}$ Another aspect of intensity is the notion that it is the individual's subjective perception which is important. Thus, if one identifies a relationship as being close, then that interpretation influences the meaning placed on the relation, which in turn influences subsequent behavior. This explanation is in keeping with the theoretical perspectives in symbolic interactionism.

Drawing from previous research findings ${ }^{62,88}$ and theory, and as developed in the conceptual framework one hypothesis of this study was that the combination of those characteristics representative of the quality of interactions within a network is more strongly related to psychological well-being than is the combination of network characteristics that indicate quantity of relationships. This hypothesis was supported by the data and provides several interesting ideas for speculation. First, the qualitative network characteristics of affective support, intensity, and reciprocal affective support seem to parallel some dimensions of the concept of social support as defined by Cobb, ${ }^{13}$ Kahn and Antonucci, ${ }^{23}$ and House ${ }^{17}$ - interactions which are characterized by care, love, handling of emotional difficulties, provision of affective supplies, and mutual obligation. Other properties that they include in their definitions are not covered by these three network characteristics, such as the provision of feedback (perhaps indirectly), communication, and instrumental support. However, the combination of these qualitative characteristics of networks may further clarify just what aspects of social support are associated with well-being, and suggests the appropriateness of using a network analytic approach as the context for measuring the concept of social support.

The significant effect of these three characteristics in combination also supports the thinking that there may be typologies or clustering of network properties with different effects on varying outcomes. ${ }^{23,40}$ For example, based on these results, a network that provides affective support, closeness, and reciprocity may positively influence psychological well-being; yet a network which provides instrumental support and close geographical proximity may be more helpful in emergency situations. Thus, such clustering of network characteristics might be determined by the needs of the individual as well as his or her personal and environmental resources and demands.

In this study, this broader context was investigated through the variables that were used as controls (i.e., marital status, per- 
ceived health status, income employment background, and use of network). No specific hypotheses were stated; rather it was the cumulative effect of these variables which was considered to be important. It is interesting to note, however, the individual effects of these factors. Perceived health status and use of network each contributed a significant amount of the variance in psychological well-being, adjusting for the other control variables. A possible explanation for why income and marital status did not have a significant effect is the homogeneity of the population on these two dimensions. The use of network variable seems noteworthy because it has not been included in many previous studies (Tolsdorf, ${ }^{19}$ being one exception). If, indeed, whether or not an individual actually uses the resources of his or her network is associated with psychological well-being, then it is not enough to analyze the characteristics of a person's network in an abstract sense. One must also investigate the extent to which the person actually turns to his or her network members.

\section{LIMITATIONS}

This study has several limitations which are common to the cross-section retrospective design of the explanatory survey methodology.

1. There is difficulty in ruling out possible rival hypotheses that may account for the findings; e.g., there may be other factors not included here, such as stress, social competence, other functional network characteristics such as provision of cognitive support, maintenance of social identity, which might be associated with well-being.

2. The data used were collected at one point in time. For any findings that show that two variables are related, it is not possible to determine which is the cause and which the effect.

3. Any findings tend to suggest stability over time, when in actuality both network characteristics and psychological well-being may change considerably if examined at different points in time.

There are several other limitations of this research which concern the study population itself. The use of a nonrandom sample, chosen with narrow selection criteria, limits the ability to gen- 
eralize the findings. A less homogeneous sample with regard to demographic characteristics might have yielded different results. Also there may be confounding between the use of the close network and the network characteristic of intensity. (Other limitations and how their effects were reduced are discussed elsewhere. ${ }^{31}$ )

\section{IMPLICATIONS FOR HEALTH EDUCATION PRACTICE}

We are increasingly involved in building networks of people-both for purposes of personal support and for purposes of social action towards a more humane world.

Carl Rogers

The elderly of this country are particularly susceptible to emotional as well as physical problems. ${ }^{91-93}$ There are numerous psychological factors which are associated with such increased risk, and in a nondisease specific way. Thus, health promotive strategies are a viable and much needed direction for health education to take. One general strategy aims to strengthen and enhance social support systems. Although there are still numerous gaps in our understanding of how social networks operate and with what effects, the results of this study provide some insights into what more specific program strategies might be taken. These will be discussed with specific focus on the role of the professional.

In general, there are four different types of programs with implications for enhancing social networks. These are: (1) programs aimed at developing new support systems, e.g., self-help mutual aid groups; (2) programs aimed at providing needed human services in a way that enhances naturally occurring networks; (3) programs aimed at enhancing the "total" network through tapping the resources of "natural helpers"; and (4) programs involving total networks and interacting networks (e.g., communities) in cooperative problem-solving and empowerment endeavors in which networks may be enhanced as a byproduct. (For examples of each of these types of programs the following partial list of references is suggested:) 32,94-100. The overall program goal may emphasize promotion, prevention, treatment, and/or rehabilitation. The role of the professional in any one of these programs may range from that of an expert or teacher in control-and, hence, creating a dependency with the lay system - to that of a facilitative colleague or learner-and, hence, establishing an interdependency with the lay system. 
Specific methods that might be used include: training, group facilitating, consultation, counseling, and community organizing.

Two of the findings of this study were that interactions characterized by high intensity and the provision of affective support were significantly related to psychological well-being. These findings suggest that health education strategies, in general, be planned and implemented in a way which encourages and enhances the development of interactions which supply feelings of caring, intimacy, and moral support. Furthermore, where appropriate, interventions could engage the participants in skill development along these affective dimensions.

This study also found an association between reciprocity and psychological well-being, from which there seem to be at least two important implications for health education practice. First, programs should aim toward facilitating participant interactions which are characterized by mutuality and interdependence. One way to accomplish this might be the use of peer counseling and education strategies, and/or self-help mutual aid groups in which the vital element of the helper-helpee relationship is its emphasis on mutual exchange and mutual problem-solving. Interventions might also assist participants to be more reciprocal in their relationships, particularly in situations where network members may feel overburdened by a preponderance of one-way "helping" interactions. A second implication of this finding is that health educators also need to strive toward establishing this same interdependence with persons involved in their programs. In such an approach professionals need to recognize the existence of lay expertise from which they can learn from and share. This seems particularly important, when working with elderly persons, who may assume, probably based on past experiences, that relationships with professionals place them in a dependent role.

Meals on Wheels, a program aimed at the provision of instrumental support, serves as an example of an intervention that may not (inadvertently) follow the suggestions made above. This program is designed to provide hot meals to individuals living alone who are not able to prepare such food for themselves. There is often little consideration or analysis made to determine whether an individual to be served already has a network member who brings not only a meal but also emotional support, intimacy, and mutual sharing. Frequently, after such an individual begins to receive meals from the program the network member feels that he or she is no longer needed and stops visiting 
as often. In addition to the potential loss of affective support, closeness, and mutual exchange, the program recipient also becomes dependent on the professional for the food (and the program may end), and often has little opportunity or resources to reciprocate.

Several general points regarding working with networks seem to follow from this research. In conducting a needs assessment with an elderly population (both as individuals and within a community context), a network analysis could be carried out and examined to discover which network characteristics are present and which are not. Health education program strategies could be designed based on the types of networks available and directed at specific identified needs. For example, in conducting a needs assessment in a neighborhood comprised of many elderly widows, problems of loneliness, depression, and fear might be identified, and a network analysis might reveal few interactions among the widows which provide caring and mutual sharing. A health education program might be developed which among other goals would aim to strengthen, affectively supportive and reciprocal relationships among the neighbors. Such an approach builds on the link between psychosocial factors and nondisease specific outcomes. Additionally, the results of this study implied that it is important to obtain an individual's subjective perception and interpretation of events not only to aid the professional in needs assessment, but also to help him or her carry out the entire program planning process. Therefore, it would seem necessary for professionals to obtain this "inside view" of individuals with whom they are working and to collaborate with them to develop programs that are appropriate to their perspectives.

With regard to these practice implications and the potential positive association that these network characteristics have with health status, the health educator must also consider: the nature of the task or crisis occurring; ${ }^{20}$ the stage of the crisis; ${ }^{20}$ the individual's need for and point at which the need is met for different functional network characteristics $;{ }^{3}$ and the individual's orientation towards using network resources; ${ }^{19,20,31}$ Thus, the complexity of identifying and collaborating with social networks becomes readily apparent. For example, whereas a recent widow may initially benefit from an intimate, high density network which provides much affective support, she may later need a network with weak, less intense ties which offers new information, social contacts, and social roles, rather than a closed set of normative expectations. ${ }^{20}$

One further role for health educators working with social net- 
works is the education of other professionals and policymakers about what networks are, how they function, and with what effects. Toward this end, it is necessary that we engage in applied, action-oriented research-involving the collaboration of researchers, practitioners, and community members. Such an approach will not only generate new knowledge and understanding of behavior science principles, but will also provide program evaluation results which can be used to influence policymakers to make decisions that will recognize, support, and strengthen social networks. However, it is especially important that the results of such decisions neither undermine these natural systems nor serve as an excuse for not providing needed human services. Furthermore, as health educators begin to place such an emphasis on the role of social networks, we should begin to realize that the individuals and networks with which we work are constrained by elements in the larger social-political-economic context, for which collaborative, social action is needed in order to achieve a more humane world.

\section{REFERENCES}

1. Lowenthal MF, Chiriboga D: Social Stress and adaptation: Toward a life course perspective. In C Eisdorfer and M Lawton (Eds). Psychology of Adult Development and Aging Washington, D.C.: American Psychological Association, 1973.

2. Rabkin JG, Struening EL: Life events, stress, and illness. Science 194:1013-1020, 1976.

3. Kaplan BH, Cassel JC, Gore S: Social support and health. Medical Care 15:47-58, 1977.

4. Liem R, Liem J: Social class and mental illness reconsidered: The role of economic stress and social support. Journal of Health and Social Behavior 19:139-156, 1978.

5. Dohrenwend BP: Stressful life events and psychopathology: Some issues of theory and method. In IR Barrett, et al. (Eds), Stress and Mental Disorder. New York: Raven Press, 1979.

6. Heller K: The effects of social support: Prevention and treatment implications. In Maximizing Treatment Gains. New York: Academic Press, Inc., 1979.

7. Jenkins CD: Psychosocial modifiers of response to stress. Journal of Human Stress 3-15, 1979.

8. Coyne $I C$, Lazarus RS: Cognitive style, stress perception and coping. In IL Kutash and LB Schleisinger (Eds), Pressure Point: Perspectives on Stress and Anxiety.San Francisco: Jossey-Bass, 1980.

9. McKinlay JB: Social network influences on morbid episodes and the career of help seeking. In L Eisenberg and A Kleinman (Eds), The Relevance of Social Science for Medicine. Dordrecht, Holland: D. Reidel Publishing Company, 1980.

10. Roskies E, Lazarus RA: Coping theory and the teaching of coping skills. In PO Davidson and SM Davidson (Eds), Behavioral Medicine: Changing Health Lifestyles. New York: Brunner-Mazel Publisher, 1980.

11. Gottlieb BH: (Ed): Social Networks and Social Support. Beverly Hills, California: Sage Publications, Inc., 1981.

12. Cassel J: The contribution of the social environment to host resistance. American Journal of Epidemiology 104:108-123, 1976. 
13. Cobb S: Social Support as a moderator of life stress. Psychosomatic Medicine 38:300-314, 1976.

14. President's Commission on Mental Health. Community supports. Task Panel Reports, Vol. II, Washington, D.C.: U.S. Government Printing Office, 1978.

15. Hamburg BA, Killilea $M$ : Relation of social support, stress, illness, and use of health services. In Healthy People: Background Papers. The Surgeon General's Report on Health Promotion and Disease Prevention, Washington, D.C.: U.S. Government Printing Office, 1979.

16. Hogue CC: Overview and prospects for research on social support of older adults. Paper presented at 32nd Annual Meeting of the Gerontological Society, Washington, D.C., November 29, 1979.

17. House JS: Work Stress and Social Support. Reading, Massachusetts: Addison-Wesley Publishing Company, 1981.

18. Mitchell JC: The concept and use of social networks. In JC Mitchell (Ed), Social Networks in Urban Situations, Analysis of Personal Relationships in Central African Towns. Manchester, England: Manchester University Press, 1969.

19. Tolsdorf CC: Social networks, support and coping: An exploratory study. Family Process 15:407-427, 1976.

20. Walker KN, MacBride A, Vachon MLS: Social support networks and the crisis of bereavement. Social Science and Medicine 11:35-41, 1977.

21. Pilisuk $M$, Froland $C$ : Kinship, social networks, social support and health. Social Science and Medicine 12B:273-280, 1978.

22. Mitchell RE, Trickett EJ: Social networks as mediators of social support: An analysis of the effects and determinants of social networks. Community Mental Health Journal 16:27-44, 1980.

23. Kahn RL, Antonucci TC: Convoys over the life course: Attachments, roles and social support. In Baltes and Brim (Eds), Life Span Development and Behavior, Vol. E, New York: Academic Press, 1980.

24. Fischer CS, Jackson RM, Steuve CA, Gerson K, Jones LM, Baldassare M: Networks and Places: Social Relations in the Urban Setting. New York: Free Press, 1977.

25. Berkman LF: Social networks and physical health: How do we measure the important factors? Paper presented at 32nd Annual Meeting of the Gerontological Society, Washington, D.C., November 29, 1979.

26. Caplan RD: Social support, person-environment fit, and coping. In L Ferman and J Gordis (Eds), Mental Health and the Economy. Kalamazoo, MI: Upjohn Institute, 1979.

27. Gottlieb BH: Social networks and social support in community mental health. In BH Gottlieb (Ed), Social Networks and Social Support. Beverly Hills, California: Sage Publications, Inc., 1981.

28. Gottlieb BH: Preventive interventions involving social networks and social support. In BH Gottlieb (Ed), Social Networks and Social Support. Beverly Hills, California: Sage Publications, Inc., 1981.

29. Wellman B: Applying network analysis to the study of support. In B Gottlieb (Ed), Social Networks and Social Support, Beverly Hills, California: Sage Publications, Inc., 1981.

30. Sarason SB, Carroll CF, Maton K, Cohen S, Lorentz E: Human Services and Resources Networks: Rationale, Possibilities, and Public Policy. San Francisco: Jossey-Bass Publishers, 1977.

31. Israel BA: Social Networks and Psychological Well-Being Among Elderly Women. Unpublished Doctoral Dissertation, Chapel Hill, N.C.: University of North Carolina, School of Public Health, 1981.

32. Israel BA: Social networks and health status: Linking theory, research, and practice. Patient Counseling and Health Education 4:65-79, 1982.

33. Bott E: Family and Social Networks. London: Tavistock Publications 1957.

34. Boswell DM: Personal crises and the mobilization of the social network. In JC Mitchell (Ed), Social Networks in Urban Situations: Analyses of Personal Relationships in Central African Towns. Manchester, England: Manchester University Press, 1969. 
35. Epstein AL: The network and urban social organization. In IC Mitchell (Ed), Social Networks in Urban Situations: Analyses of Personal Relationships in Central Africa Towns. Manchester, England: Manchester University Press, 1969.

36. Wheeldon PD: The operation of voluntary associations and personal networks in the political processes of an interethnic community. In JC Mitchell (Ed), Social Networks in Urban Situations. Manchester, England: Manchester University Press, 1969.

37. Kapferer B: Norms and the manipulation of relationships in a work context. In IC Mitchell (Ed), Social Networks in Urban Situations. Manchester, England: Manchester University Press, 1969.

38. Laumann EO: Bonds of Pluralism: The form and Substance of Urban Social Networks. New York: John Wiley and Sons, 1973.

39. Stack CB: All Our Kin. New York: Harper and Row, 1974

40. Havighurst RH, Neugarten BL, Tobin SS: Disengagement and patterns of aging. In BL Neugarten (Ed), Middle Age and Aging. Chicago: The University of Chicago Press, 1968.

41. Maddox, GL: Persistence of life style among the elderly. In BD Neugarten (Ed), Middle Age and Aging. Chicago: The University of Chicago Press, 1968.

42. George L: The impact of personality and social status factors upon levels of activity and psychological well-being. Journal of Gerontology 33:840-847, 1978.

43. Conner KA, Powers EA, Bultena GL: Social interaction and life satisfactions: An empirical assessment of late-life patterns. Journal of Gerontology 34:116-121, 1979.

44. Palmore E, Cleveland WP, Nowlin JB, Ramm D, Siegler I: Stress and adaptation in later life. Journal of Gerontology 34:841-851, 1979.

45. Sokolovsky J, Cohen C, Berger D, Geiger ): Personal networks of ex-mental patients in a Manhattan SRO hotel. Human Organization 37:5-15, 1978.

46. Wilcox BL: Social support in adjusting to marital disruptions: A network analysis. In BH Gottleib (Ed), Social Networks and Social Support. Beverly Hills, California: Sage Publications, Inc., 1981.

47. Berkman LF, Syme SL: Social networks, host resistances, and mortality: A nineyear follow-up study of Alameda County residents. American lournal of Epidemiology 109:186-204, 1979.

48. Schaefer C, Coyne IC, Lazarus RS: The health-related functions of social support. Journal of Behavioral Medicine 4:381-406, 1981.

49. Froland C, Brodsky C, Olson M. Stewart L: Social support and social adjustment: Implications for mental health professionals. Community Mental Health Journal 15:82-93, 1979 .

50. Felton BJ, Hinrichsen GA, Tsemberis S: Urban-suburban differences in the predictors of morale among the aged. Journal of Cerontology 36:214-222, 1981.

51. Liang J. Dvorkin L, Kahana E, Mazian F: Social integration and morale: A re-examination. Journal of Gerontology 35:746-757, 1980.

52. Hoyt DR, Kaiser MA, Peters GR, Babchuk N: Life satisfaction and activity theory: A multidimensional approach. Journal of Gerontology 35:935-941, 1981.

53. Schwartz H, Jacobs 1: Qualitative Sociology: A Method to the Madness. New York: The Free Press, 1979.

54. Fisher BM, Strauss AL: Interactionism. In T Bottmore and R Nisbet (Eds), A History of Sociological Analysis. New York: Basic Books, Inc., 1978.

55. Homans GC: Social Behavior: Its Elementary Forms. New York: Harcourt Brace Jovonovich, 1961.

56. Blau PM: Exchange and Power in Social Life. New York: Wiley, 1964

57. Emerson RM: Social exchange theory. In A Inkeles, I Coleman, and N Smelser (Eds), Annual Review of Sociology, Vol. 2, Palo Alto, CA: Annual Reviews, Inc., 1976.

58. Bredemeier HC: Exchange theory. In T Bottmore and R Nisbet (Eds), A History of Sociological Analysis. New York: Basic Books, Inc., 1978.

59. Dowd II: Aging as exchange: A preface to theory. Journal of Gerontology 30:584-594, 1975.

60. Dowd II: Exchange rates and old people. Journal of Gerontology 35:596-602, 1980. 
61. Dean A, Lin N, Ensel WM: The epidemiological significance of social support systems in depression. Paper presented at the 107th annual meetings of the American Public Health Association, New York, New York, November 4-8, 1979.

62. Lowenthal MF, Haven C: Interaction and adaptation: Intimacy as a critical variable. American Sociology Review 33:20-30, 1968.

63. Moriwaki SY: Self-disclosure, significant others and psychological well-being in old age. Journal of Health and Social Behavior 14:226-232, 1973.

64. Gore S: The effect of social support in moderating the health consequences of unemployment. Journal of Health and Social Behavior 19:157-165, 1978.

65. Nuckolls KB, Cassel ), Kaplan BH: Psychosocial assets, life crises and the prognosis of pregnancy. American lournal of Epidemiology 95:431-441, 1972.

66. LaRocco IM. House JS, French JRF: Social support, occupational stress, and health. Journal of Health and Social Behavior 21:202-218, 1980.

67. Bradburn NM: The Structure of Psychological Well-Being. Chicago: Aldine, 1969.

68. Gorton A: A network analytic approach to assess social support systems of retired women. Paper presented at the 32nd Annual Meeting of the Gerontological Society. Washington D.C., November 29, 1979.

69. Gurin C, Veroff J, Feld S: Americans View Their Mental Health. New York: Basic Books, Inc., 1960.

70. Langner TS, Michael ST: Life Stress and Mental Health. London: The Free Press of Glencoe, 1963.

71. Berkman PL: Life stress and psychological well-being: A replication of Langner's analysis in the midtown Manhattan study. Journal of Health and Social Behavior 71:35-45, 1970.

72. Srole L: Measurement and classification in socio-psychiatric epidemiology: Midtown Manhattan study (1954) and Midtown Manhattan re-study (1974). Journal of Health and Social Behavior 16:347-364, 1975.

73. Wildman RC, Johnson DR: Life change and Langner's 22-item mental health index: A study and partial replication. Journal of Health and Social Behavior 18:179-188, 7977.

74. Hogue CC: Personal communication, 1980.

75. Gorton A: Personal communication, 1980.

76. Fisher CS, Jackson RM, Steuve CA, Gerson K, Jones LM, Baldassare M: Networks and Places: Social Relations in the Urban Setting. New York: Free Press, 1977.

77. Jones LM, Fischer CS: Studying egocentric networks by mass survey. Working Paper No. 384, Institute of Urban and Regional Development, University of California, Berkeley, 1978.

78. McCallister L, Fischer CS: A procedure for surveying personal networks. Sociological Methods and Research F:131-148, 1978.

79. Bradburn NM, Caplovitz D: Reports on Happiness: A Pilot Study of Behavior Related to Mental Health. Chicago: Aldine, 1965.

80. Matlin N: The demography of happiness. Master Sample Survey of Health and Welfare, Series 2, No. 3, Commonwealth of Puerto Rico, Department of Health, 1966.

81. Beiser $M$ et al: Assets and affects. Archives of General Psychiatry 27:545-549, 1972.

82. Lawton MP: Morale: What are we measuring? In CN Nydegger (Ed), Measuring Morale: A guide to Effective Assessment. Washington, D.C.: The Gerontological Society, 1977.

83. George LK, Bearon LB: Quality of Life in Older Persons: Meaning and Measurement. New York: Human Sciences Press, 1980.

84. Caplan RD, Robinson EAR, French JRP, Caldwell JR, Shinn M: Adhering to Medical Regimens: Pilot Experiments in Patient Education and Social Support. Ann Arbor: Institute for Social Research, 1976.

85. Duke Center for the Study of Aging and Human Development. Multi-dimensional Functional Assessment: The OARS Methodology (Second Edition). Durham, N.C.: Center for the Study of Aging and Human Development, 1978.

86. Barr Al, Goodnight JR, Sall IP: SAS User's Guide. Raleigh, N.C.: SAS Institute Inc., 1979. 
87. Dean A, Lin N: The stress-buffering role of social support. The Journal of Nervous and Mental Disease 165:403-417, 1977.

88. Porritt D: Social support in crises: Quantity or quality? Social Science and Medicine 13A:715-721, 1979.

89. Israel BA: Social Networks and Support Systems: Impact on Personal Well-Being. Unpublished Masters Thesis, Chapel Hill, N.C.: University of North Carolina, School of Public Health, 1978.

90. Granovetter M: The strength of weak ties. American Journal of Sociology 78:1360-1380, 1973.

91. Rosenfeld $\mathrm{AH}$ : New Views on Older Lives. NIMH, Washington, D.C.: Publication No. (ADM) 78-687, 1978.

92. Birren JE, Renner VJ: A brief history of mental health and aging. Volume I, U.S. Dept of HEW, PHS, ADAMHA, DHEW Publication No. (ADM)79-663, 1979.

93. Hagebak JE, Hagebak BR: Serving the mental health needs of the elderly: The case for removing barriers and improving service integration. Community Mental Health Journal, 1980.

94. Collins AH, Pancoast DL: Natural Helping Networks: A Strategy for Prevention. New York, National Association for Social Workers, 1976.

95. Katz A, Bender E: The Strength in Us: Self-Help Groups in the Modern World. New York: Franklin-Watts, 1976.

96. McKnight I: Community Health in a Chicago slum. Development Dialogue: A Journal of International Development 1:62-68, Dag Hammarskjold Foundation, 1978.

97. Gartner A, Riessman F: Help: A Working Cuide to Self-Help Croups. New York: New Viewpoints/Vision Books, 1980.

98. Pilisuk M.. Minkler M: Supportive networks: Life ties for the elderly. Journal of Social Issues 36:95-116, 1980.

99. Froland C, Pancoast DL, Chapman NJ, Kimboko PJ: Helping Networks and Human Services. Beverly Hills, California: Sage Publications, Inc., 1981.

100. Minkler $\mathrm{M}$ : Applications of social support theory to health education: Implications for work with the elderly. Health Education Quarterly 8:147-165, 1981. 